

\title{
Size Factors as Determinants of Recurrent Unit Cost of Public Secondary Education in Edo State, South-South Nigeria
}

\author{
Eragbai Jerome Isuku
}

\author{
Department of Educational Management, \\ University of Ibadan, Ibadan, Nigeria \\ Email: jeromeisuku72@gmail.com
}

Doi:10.5901/jesr.2016.v6n3p125

\begin{abstract}
This study, investigated the influence of school size factors (enrolment, average-class-size and student-teacher-ratio) on the recurrent unit cost of public secondary education in Edo State, Nigeria. The study adopted the descriptive survey design. This design was considered appropriate because it provided a strategy for obtaining and describing the existing conditions without any manipulation. The multi-stage sampling techniques were used to select 207 out of the total 509 conventional public secondary schools across the State. Two inventories were used to collect secondary data from the 207 schools and the State Ministry of Education officials. The school inventory was used to obtain data on individual school size features and recurrent expenditures while the inventory for Ministry of Education was used to collect aggregate school enrolment, classes, staff and recurrent expenditures. Two research questions were raised, while data were analyzed using the multiple regression technique. Result indicate that Size factors had significant influence on the recurrent unit cost of public secondary education $\left(F_{(6,163)}=32.6 ; p<0.05\right)$. They jointly accounted for $49 \%$ of the variation in recurrent unit cost. The relative contributions of the independent variables were as ranked: enrolment $(\beta=-0.71 ; t=-6.14 ; p<0.05)$, student-teacher-ratio $(\beta=-0.66 ; t=-3.34$; $p<0.05)$ and average-class-size $(\beta=-0.40 ; t=-1.75 ; p<0.05)$. This implied that enrolment and student-teacher-ratio factors were the strongest predictors of unit cost. All the three size factors were inversely related to unit cost. A marginal unit increase in enrolment; average-class-size and student-teacher-ratio reduced recurrent unit cost by N113.92, N234.01 and N584.85 respectively. The relationship between expanding the size factors and recurrent unit cost was U-shaped, indicating that there were optimum sizes for the various size factors. These were: enrolment- 712 students per school, average-class-size- 45 students and student-teacher ratio- 50:1 respectively Enrolment and Student-teacher-ratio factors had significant influence in the reduction of recurrent unit cost of public education. Therefore, enrolment and student-teacher-ratio could be increased to the optimum level as a cost reduction strategy in public schools. This could be achieved through merger of small-sized inefficient schools.
\end{abstract}

Keywords: Enrolment, Average-class-size, Student-teacher-ratio, Recurrent unit cost.

\section{Introduction}

The role of School size factors (School enrolment, average-class-size and student-teacher-ratio) in the determination of recurrent unit cost in schools have raised and may continue to raise serious concern about school management plan and policy issues As government at all levels continue to bear the increasing financial burden of education in the face of other pressing macroeconomic challenges, the need to ensure effective and efficient resource utilization in school service delivery becomes very germane

Although it is the desire of the government to provide secondary school access to all eligible primary school leavers (National Policy on Education, Federal Republic of Nigeria 2004), the cost of achieving this laudable objective has made the continues expansion of secondary education unsustainable (Isuku, 2011; Isuku and Emunemu 2012). However, in an effort to provide increased access to secondary education for the growing number of primary school graduates, governments at various levels has built public secondary schools in almost every location characterized with mixed enrollments sizes. While some schools are heavily populated with students, some have very few students enrollment. Similarly, there are noticeable differences in other size features like average-class-size and student-teacherratios.

Generally, the growth of secondary schools in Nigeria at both national and state levels has been on the increase over the years. Available data revealed that public secondary school in Nigeria increased from 6,909 in 2002 to 10,570 in 2003 and 18,388 in 2006 ( Federal Ministry of Education 2009). In the same vein, the total student enrollment for 
these years stood at 4,897,048 million in 2002; 6, 509,722 million in 2003, and 6, 5326,938 million in 2006 respectively. These enrollment figures represent an average of 708,615 and 316 students per school respectively. However, contrary to the increasing trends in enrolment at the Federal level, Edo State has experienced a general decline in enrolment at the secondary level. Available data show that in 1995, a total of 212,379 students were enrolled in the 297 secondary schools. This number then declined to 134,322 pupils in 1996 (Federal Office of Statistics 1999). By 2005, the total number of students enrolled in Edo State public secondary schools stood at 176,172 while it later declined to 150,354 students in 2006 (NBS, 2007). The data revealed that the average number of students per school in the state declined from 914 in 1992 to 841 in 1994. It further declined to 545 and 483 students per school in 1996 and 1998 respectively (FME, 2003; Olaniyi and Adam, 2003; FOS, 1994). At the beginning of the Democratic era in 1999, the mean enrolment momentarily increased to 1034 before it started to decline again to 871 and then to 1120 students per school in 2000 and 2001 respectively. Table 1 show the trend in secondary school sizes in Edo State public secondary schools from 1999 to 2006.

Table 1: Trends in secondary school size in Edo State, Nigeria 1999 - 2008

\begin{tabular}{|c|c|c|c|c|c|}
\hline Year & $\begin{array}{c}\text { No of Secondary } \\
\text { Schools }\end{array}$ & $\begin{array}{c}\text { Total } \\
\text { Enrolment }\end{array}$ & $\begin{array}{c}\text { Average School Size } \\
\text { (ASS) }\end{array}$ & $\begin{array}{c}\text { Average- Class-Size } \\
\text { (ACS) }\end{array}$ & $\begin{array}{c}\text { Student- Teacher- Ratio } \\
\text { (STR) }\end{array}$ \\
\hline 1999 & 293 & 303,194 & 1034 & 73.3 & 1.35 \\
\hline 2000 & 293 & 255,168 & 871 & 34 & 1.29 \\
\hline 2001 & 293 & 328,225 & 1120 & 37 & 1.37 \\
\hline 2002 & 285 & 252,473 & 885 & 23.2 & 1.26 \\
\hline 2003 & 652 & 267,572 & 410 & 9 & 1.27 \\
\hline 2004 & 540 & 173,361 & 321 & 44 & 1.18 \\
\hline 2005 & 540 & 176,172 & 326 & 45 & 1.28 \\
\hline 2006 & 918 & 150,354 & 163 & 38 & 1.28 \\
\hline 2007 & 918 & 53,063 & 58 & Na & na \\
\hline 2008 & 918 & 173,908 & 190 & Na & \\
\hline
\end{tabular}

Source: Computed from data obtained from Statistics of Education in Nigeria. FME, 2007, NBS, 2007 Annual abstract of statistics and Edo State Directory of Secondary Education, 2008 in place of Ministry of Education, Department of Planning and Statistics, 2007

Available data showed that the total gross enrolment in the state public secondary schools declined from 303,194 during the beginning of the democratic era in 1999 to 255,168 in 2000. The enrolment figure however increased to 328,225 in the succeeding year 2001. In 2002, the figure again fell to 252,473 pupils. By 2006, the total gross enrolment in the state public secondary schools fell to an all-time low of 150,354. A striking feature is that while the general enrolment declines, the average school size (enrolment per school), average-class-size and student-teacher-ratio also declined during the period. For example, the average school size in the state public schools declined steadily from 1034 students per school in 1999 to 410 in 2003, and then to 163 students per school in 2006. The average-class-size in the state public secondary schools equally declined from about 73 students per class in 1999 to 34 students per class in year 2000. In 2003, the average-class-size in the state public secondary schools dropped to as low as 9 students per class while it latter rose to an average of 38 students per class in the year 2006. Thus, the average class size of students in the state's public secondary schools during the eight year period under consideration stood at 37 per class.

On the other hand, available data from the table show that the student-teacher-ratio for the period under consideration was highest in 2001 when the STR was 37:1, while it was lowest in 2004 with a STR of 18:1. The trend as revealed in the table show a consistent overall decline in the Average School Size (Enrolment), Average-Class-Size (ACS) and the Student-Teacher-Ratio (STR) over the years in the state public secondary schools. The argument for reduced ACS and STR is based on the quality value of reduced class-size and student-teacher-ratio. Proponents of this argument are of the belief that a reduced ACS and STR will improve teacher/student interaction in schools and that teachers will be able to pay personal attention to student's need (Cotton 1996). However, different countries have different priorities for increasing or reducing school sizes. For instance, Korea encourages high class size in an attempt to sustain the payment of high salaries to teachers Lewin (2001). Moreover, many studies have shown that smaller class size does not guarantee that children get better attention (Hanushek 1996, Carnoy 1999 and Turtel 2006). For instance, Turtel (2006) found that student-teachers-ratio in OECD countries dropped from 24:1 in the 1960s to 17:1 in 1990s, (a 
drop of 28 percent), yet the Scholastic Aptitude Test (SAT) test score conducted in those countries according to Turtel revealed a downward trend in performance from 954 to 896, a decline of 58 points or 6 percent. In other words, students' academic performance as measured by SAT scores dropped at the same time as class sizes got smaller in those countries. This imply that other factors other than class size may be responsible for student quality outcome in schools

In an effort to keep pace with reduced school sizes (measured by average enrolment per school, average-classsize and student-teacher-ratio) over the years, it is expected that additional teaching and non-teaching personnel will be employed; materials and other necessary school equipment need to be provided. Moreover, maintenance of school plant and other school facilities will need to be provided in other to enhance effective and efficient service delivery in schools. All of these usually have their cost implication on tax payers and the government's financial resources and consequently results in an overall increase in government expenditure on education (Adedeji, Olaniyan\&Owoeye, 2001; Adenuga, 2003 and Ibukun, 2004). For instance, Federal government recurrent expenditure on secondary education increased from 3.2 million naira in 1970 to 7.3 million naira in 1972, while the capital outlay rose from 3.0 million naira to 21.3 million naira during the same period. As at 1975 recurrent expenditure on secondary education has increased to 218.9 million naira. While the recurrent expenditure for education in 1990 and 2000 stood at 3,402 million naira and 39,034.0 million naira respectively (Adenuga, 2003). Similarly, in Edo State, the total recurrent expenditure on public secondary school education was 2,017.2 million naira in 2001. In 2003 and 2004, the total recurrent expenditure stood at 2,353.5 and 2,303.0 million naira respectively. By 2005, the recurrent expenditure was 3,385.5 million naira. While it stood at 3,501.4 and 5,027.07 million naira in 2006 and 2007 respectively (Edo State Directory of Public Secondary Institutions, 2005 and Edo State Ministry of Education 2008). All of these imply an increased cost burden on the government in an effort to provide secondary school education to the school-age children in the face of other competing macro-economic needs.

\section{Statement of the Problem}

There is growing concern about the problem of insufficient and relatively declining funding of public schools. This problem has been compounded by the inefficient use of limited resources in schools. As governments continue to shoulder an increasing burden of the financing of secondary education in the face of other pressing public needs such as health, agriculture, and infrastructural development etc, there is a heavy financial burden of education on the government. This problem has the capacity to restrict access, resource availability, quality and overall educational development. This study therefore was an attempt to investigate the extent to which ( school enrolment, class size and student-teacher-ratio) size factors could determine the recurrent unit cost of public secondary education in Edo State public secondary Schools with a view to explore ways of improving control over the rising cost of public schools in the state..

\subsection{Research Questions}

In an effort to investigate the effect of these size factors on the operational cost of public schools in the state, two research questions were. Viz;

1. R.Q 1. What is the relative contribution of the respective size factors on recurrent unit cost in the sampled schools?

2. R.Q 2. To what extent do size factors jointly determine recurrent unit cost in the sampled public secondary schools in the state?

\section{Theoretical Framework}

The theoretical bases upon which this research was built were the production and cost theories. The production theory focuses on the efficient use of various inputs in the provision of school output.. It applies the production function theory which describes the technical relationship between outputs of the school services, and the resource inputs (teachers, non-teachers, fund etc). It is mathematically expressed as $Q=f(a, b, c . . n$

Where $\mathrm{Q}$ is the output while $a, b, c . . . \mathrm{n}$ are the different resources used in the production process. The school requires various inputs such as teachers, non-teaching staff, material resources etc to produce a range of educational output. However, owing to the difficulty of measuring the school variables appropriately (Cohn 1979, Matthew 2003), the cost function was employed to capture the amount of expenditure incurred in the course of producing the school 
services. Drawing from the production function framework adapted from Cohn, 1979, Chakrabourty, Biswas \& Lewis, 2003 and Chiang, 1994) we have $\mathrm{f}(\mathrm{Q} i, \mathrm{X} / \mathrm{S})=0$

Where Qi is the output vector, $X=$ the school variables (e.g. teachers, materials etc) while $S=$ non-school related variables (non-manipulative variables, and $\mathrm{O}=$ school output. We include the school size variable denoted by $\mathrm{E}$ (enrolment). The square of the enrolment variable will allow for a U-shaped cost function in order to capture for the nonlinearity. Estimate is then provided to determine the minimum cost enrolment level. Thus with the inclusion of size variable $(E)$, we now have;

$\mathrm{f}(\mathrm{Qi} X, \mathrm{E} / \mathrm{S}=0$

Therefore using the real financial outlay (accounting cost) prices are then estimated for $X_{1}$ inputs represented by $P_{1}, P_{2}, P_{3} \ldots . . P_{11}$ where $X i$ is the quantity of input-variable with unit price $P$. thus the cost of $X i$ inputs was now given as: $C=\sum_{i=1}^{n} \quad P_{1} X_{1}=P_{1} X_{1}+P_{2} X_{2}+P_{3} X_{3} \ldots \ldots . P_{n} X_{n}$

The minimum cost for each level of output is obtained by examining the different combinations of $X i$ which provides the same quantity of output. After some manipulation the optimum input level for producing a given level of output can then be determined. Thus the economic cost level is then given in

$$
c=\sum_{i=1}^{n} P_{1} X_{1}^{*}
$$

Where $X^{*}$ is dependent in this case on the enrolment variable (see Cohn 1979).

This theory argued that the cost-size relationship is U-shaped. In other words, drawing from the law of variable proportion (see Chiang 1994), as the school size (enrolment) increases relative to a fixed school plant, the per-pupil cost will decrease up to a-point, reach the minimum and then begin to rise at further increase in enrolment.

\section{Model Specification and Estimation}

The model applied in the study was derived from the production and cost theories based on the law of variable proportion and adapted from Chiang (1984). The law states that as more and more variable inputs are added to a fixed factor the average expenditure will gradually decline, equal to zero and then begin to rise. Therefore, given a variable cost function;

$$
\mathrm{VC}=\mathrm{VC}(\mathrm{Q})
$$

Where $\mathrm{Q}$ is a vector of output from the education production process, we can define the average variable cost (unit cost of education) function as the ratio of two functions of $Q$, since

$$
\mathrm{AVC}=V C^{1} \frac{(Q)}{Q}
$$

and this is defined as long as $\mathrm{Q}>\mathrm{O}$

Thus, to determine the rate of change of the AVC as Q changes, we apply the quotient rule of differentiation on equation (2), given;

$$
\begin{aligned}
& \frac{d}{d \underline{Q}} \frac{V C(\underline{Q})}{Q}=\frac{\left[V C^{1}(\underline{Q}) \cdot \underline{Q}-V C(\underline{Q}) \cdot l\right]}{\underline{Q}^{2}} \\
& =\frac{l}{\underline{q}}\left[V C^{1}(\underline{Q})-\frac{V C(\underline{Q}}{\underline{Q}}\right] \ldots \ldots \ldots \ldots \ldots \ldots
\end{aligned}
$$

Since the derivative $V C^{1}(\underline{Q})$ represents the addition to variable cost resulting from the production of an additional $\frac{v c(\underline{\underline{Q}})}{\underline{Q}}$

unit of output (marginal cost) and $\underline{\underline{Q}}$ represents the AVC function, equation (3) can be interpreted to obtain the shape of the AVC function.

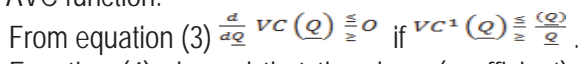

Equation (4) showed that the slope (coefficient) of a regression function of the AVC will be negative, zero, or positive if and only if the cost of additional student is less than the AVC (economies of scale), equals the AVC or greater than the AVC (Diseconomies of scale) since production is in the short-run whereby additional variable inputs are combined with the same fixed inputs, it is therefore expected that the AVC will display a U-shaped (Quadratic function).

Hence, in explicit form, equation (2) becomes AVC $=\beta_{0}+\beta_{1} \underline{Q}+\beta_{2} Q^{2} \ldots$

According to equation (4) the aproari expectation is that:

$$
\beta_{1}<0 \& \beta_{2}>0
$$

Moreover, recognizing that $\underline{\underline{Q}}$ is a vector comprising enrolment $\left(X_{1}\right)$, average-class- size $\left(X_{2}\right)$ and student-teacherratio $\left(X_{3}\right)$ equation (5) becomes;

$$
A V C=\beta_{0}+\beta_{1} X_{1}+\beta_{2} X_{2} \beta_{3} X_{3}+\beta_{4} X_{1}^{2}+\beta_{5} X_{2}^{2}+\beta_{6} X_{3}^{2}
$$


If equation 6 above is made stochastic an error term is included given as below.

$A V C=\beta_{0}+\beta_{1} X_{1}+\beta_{2} X_{2} \beta_{3} X_{3}+\beta_{4} X_{1}^{2}+\beta_{5} X_{2}^{2}+\beta_{6} X_{3}^{2}+e$

Based on the theoretical framework, we expect a non-linear relationship - specifically quadratic between unit cost and output, which in this present study are the size factors (enrolment, average-class-size and student-teacher-ratio). However, given the disagreement in the empirical literature as to the ideal functional form, it was crucial that we fit both the linear and quadratic functions to our data. Equations (1) and (2) below were therefore estimated to initially determine the appropriate functional form in which the size factors will enter the regression analysis. Thus we have:

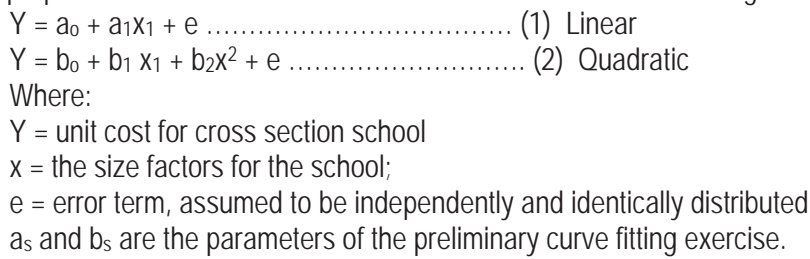

Moreover, other aspects of this study imply how equations (1) and (2) were estimated. Three measures of size (scale) factors - namely: Enrolment (En), Average-Class-Size (ACS) and Student-Teaching-Ratio (STR) were adopted in this study. Therefore, given that the curve fitting was done in a bi-variety sense, we therefore estimated each of equation (1) and (2) separately for each of the three size factors serving as the X-variable. Comparison between the equations was made to obtain the coefficient of determination $\left(R^{2}\right)$ and the shape of the curve. The regression technique was used to estimate the stipulated equation. The statistics of interest included the marginal influence of the various size factors, as well as the R-square which showed the explanatory power of the estimated model. It was therefore possible to determine the optimum sizes and the associated unit cost by exploring the range over which an increase in each of the size factor will lower unit cost (economies of scale) and the range over which changes in enrolment will raise unit cost (diseconomies of scale). The procedure entails the partial differentiation of the estimated quadratic equation. The values of the optimum sizes are then fitted into equation (2) to determine the minimum unit cost.

\section{Methodology}

The study utilized the descriptive survey research design to conduct research.Its population consisted of the existing 509 public.Secondary School and their principals in the in the state as at the time the study was conducted. The multi-stage, stratified and random sampling techniques were used respectively. These sampling techniques were used to select 207 or 40 per cent of the principals from the respective schools according to the number and size of schools in each of the three Senatorial districts in the state.Two inventory instruments were developed by the researcher to obtain relevant school records from each of the school's principal in t5he sampled schools and officials of the state ministry of Education. The data obtained include: students enrolment, classrooms, number of teachers, as well as data school recurrent expenditure from the state ministry of Education. The data collected were analyzed using multiple regression statistical technique.

\section{Study Area}

The study was carried out in Edo State, Nigeria. The state is located in the oil-rich South - South geopolitical zone of the country. According to the National Bureau of Statistics (NBS 2010), the state's population stood at 3.213,332 million with 13 different languages spoken within the state. The dominant tribes in the state are the Binis (Edo South), the Ishans (Edo Central) and the Afemai (Edo North). The state lies within the rain forest zone of the country with an annual mean rainfall of 196.5 millimeters and a minimum and maximum temperature of 23.7 and 32 degrees centigrade respectively. 


\section{Results and Discussion}

7.1 R.Q 1. What is the relative contribution of the respective size factors on recurrent unit cost in the sampled schools?

Table 2: Relative contribution of size factors to recurrent unit cost in the sampled public schools

\begin{tabular}{|l|c|c|c|c|c|}
\hline Size factors & \multicolumn{2}{|c|}{ Unstandardized Coefficient } & Standardized coefficient & T & Sig. \\
\hline & B & Std. Error & Beta & & \\
\hline Constant & 69964.5 & 3815.91 & & 18.33 & .000 \\
\hline Enrolment (EN) & -133.92 & 16.40 & -0.71 & -6.94 & .000 \\
\hline ACS & -234.01 & 133.50 & -0.395 & -1.75 & .081 \\
\hline STR & -584.85 & 175.16 & -0.656 & -3.33 & .001 \\
\hline EN Sqd. & .080 & 0.015 & 1.032 & 5.43 & .000 \\
\hline ACS Sqd. & 1.978 & 1.013 & 0.414 & 1.95 & .052 \\
\hline STR Sqd & 4.537 & 1.939 & 0.444 & 2.33 & .020 \\
\hline
\end{tabular}

Dependent variable: Unit cost.

The result in table showed the relative contributions of the size factors to recurrent unit cost. The relative influence of enrolment on recurrent unit cost was $(=-0.71 ; P<0.05$ while student-teacher-ratio factor was $(=-0.66 ; p<0.05$. The marginal influence of the size factors on recurrent unit cost were; enrolment $=$ N113.92k, average-class-size $($ ACS $)=$ N234.01k and student-teacher-ratio (STR) = N584.85k respectively. The square of the sizes showed positive signs indicating an increase in unit cost in the long-term.

7.2 RQ 2. To what extent do size factors jointly determine recurrent unit cost in the sampled public secondary schools in the state?

This question was to find out the composite effects of the size factors on the recurrent unit cost in the sampled schools.

Table 3: Joint effects of size factors on recurrent unit cost of public secondary schools in Edo State

\begin{tabular}{|c|c|c|c|c|c|}
\hline & Sum of squares & Df & Mean Score & F & Sig. \\
\hline Regression & $2.3 \mathrm{E}+01$ & 6 & 3809236280 & & \\
Residual & $2.3 \mathrm{E}+01$ & 193 & 116779165 & 32.621 & .000 \\
Total & $4.5 \mathrm{E}+01$ & 199 & & & \\
\hline
\end{tabular}

Note:
a. Predictors: (constant), EN, ACS, STR, EN sqd, ACS sqd, STR sqd.
b. Dependent variable: Recurrent unit cost
c. $R$ Square $=0.504$
d. Adjusted R Square $=0.488$

The result in table 2 showed that size factors had joint significant effect on recurrent unit cost of public secondary schools in Edo state $\left(F_{(6.193)}=32.6 ; p<0.05\right)$. The size factors (enrolment, average-class-size and student-teacher-ratio) jointly accounted for 49 percent variation in the recurrent unit cost of public secondary education in Edo State. 
Table 4: Summary of Regression analysis of the joint and relative effects of size factors on recurrent unit cost of public secondary schools in Edo-State (urban, rural and aggregate)

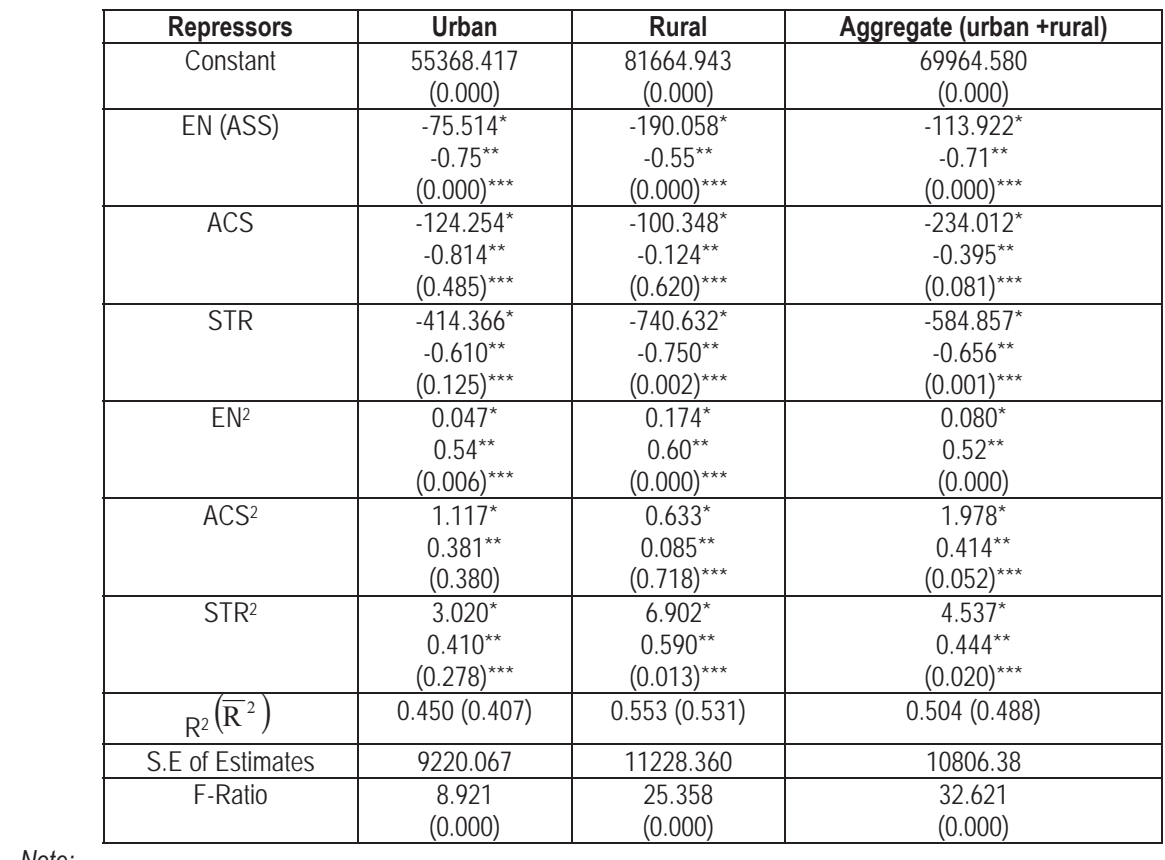

*Marginal impact of each of the size factors;

** Relative (beta) strength of each of the size factor;

*** are the P-Values of the regressors.

Table 3 is a summary of the tables 1 and 2 showed that size factors can predict unit cost in the sampled schools. The predicting power (goodness of fit) $R^{2}$ is 45 percent in urban, $55 \%$ in rural and 50 percent on the aggregate, while the explanatory power (adjusted $\mathrm{R}^{2}$ ) ranges from 40.7 percent in urban model to 53.1 percent in the rural and about, 49 percent at the aggregate sample. This explanatory power showed that size can predict unit cost more in rural schools than in urban schools.

\section{Discussion}

Results from the study showed that the F-ratio test for urban (8.921), rural (25.358) and at the aggregate (32.621) were all highly significant at $1 \%$ level $(p<0.001)$ implying that size factors were highly and jointly significant in determining the recurrent unit cost of public secondary education in the State. The coefficient of the model showed that all the parameters are appropriately signed to reflect the relationships that exist between the size factors and the recurrent unit cost. It was observed that unit cost fell initially (in the short term) over each size factor but latter rose as the size factors increases (i.e. in the long term). The value of the constant in the model indicated that in the absence of the size variables, unit cost in urban schools will amount to N55, 368.41k, N81, 664.94k in rural schools and N69, 964.58k at the aggregate level respectively. This showed the added importance of the size factors in the operation of the school system.

In terms of the relative significance of each of the size factor in the different sample locations, it was observed that enrolment (EN) was very significant in the determination of unit cost at all the sampled locations $(p<0.001)$. Averageclass-size (ACS) was not significant at both rural and urban levels of the sample location. The student-teacher-ratio variable (STR) was however significant in the determination of unit cost of schooling at the rural sample $(p<0.05)$ and at the aggregation $(p<0.05)$ but was not significant at the urban sample. Thus, at the aggregate model, only enrolment and STR factors were significant at $5 \%$ level $(p<0.05)$ while ACS is only significant at $10 \%(p<1.00)$. 
In comparing the unit cost (UC) movement over the scale factors between rural and urban schools, it was observed that the rate at which unit cost falls initially over enrolment was larger in rural schools (N190.058) than in urban schools (N75.514) and is the same for the rate at which unit cost rises at higher level of enrolment i.e. 0.047 in urban and 0.174 in rural schools. However, it is observed that unit cost falls more with average-class-size in urban (N124.25) than in rural schools (N100.348) and also rises more steeply in urban schools. On the student-teacher-ratio (STR) effect on unit cost, it observed that unit cost falls more in rural schools (N740.632) than in urban schools (N414.366). Thus, the effect of student-teacher-ratio (STR) on unit cost is greater in the short term in rural schools than in urban schools. Similarly, in the long term, unit cost in rural schools rises higher (6.902) over an increase in STR than in urban schools (3.020)

While comparing the optimum scale factors for all the three size variables in all the three sample location, it was found that average school size (enrolment) was optimized at 826 students in urban schools while it was optimized at 546 students in rural secondary schools. Similarly, it was discovered that average-class-size (ACS) and student-teacher-ratio (STR) were optimized at 46 and 59 students respectively in urban schools. At the aggregate level, we found enrolment to be optimized at 712 students per school. While the optimum average-class-size (ACS) and student-teacher-ratio (STR) were approximately 45 and 50:1 students respectively.

The minimum recurrent average cost (AC) for which enrolment was optimized in urban schools was N25, 060.82k and N29, 765.46 in rural schools. At the aggregate sample, enrolment was optimized when the recurrent unit cost was N29, 407.63k. The minimum unit cost for which ACS was maximized in urban school is N51, 913.05k while it is N77, $688.004 \mathrm{k}$ and $\mathrm{N} 63,044.66 \mathrm{k}$ in rural and aggregate samples respectively. The minimum average cost for an optimum STR size in urban and rural schools stood at N41,155.383k and N61,780.25k while it is N51,117.28k at the aggregate. Generally, the minimum average recurrent cost (UC) at which all the size factors were optimized in urban schools amounted to N33, 124.48k; N5, 290.62k in rural schools and N6, 640.74k at the aggregate level

The result of the regression analysis (table4.7) showed the effect of the autonomous variable (constant) on the recurrent unit cost of secondary education at all the sample locations. The result indicated that holding the explanatory size factors constant, the total recurrent unit cost of schooling at both urban and rural location amounted to N55, 368.41k and N81,664.58k respectively, while it amounted to N69, 964.580 on the aggregate. This result showed the added importance of the size factors in the determination of recurrent unit cost in public secondary schools. In other words, without the intervention of the size factors in public schools' operation, significant recurrent unit cost would be incurred to the tune of about N70, 000 on the aggregate per annum. In order to achieve an efficient educational service delivery in public schools, effort should be directed at reducing the unit cost of education through an aggressive student's mobilization. This could be achieved by increasing the sizes of enrolment, student-teacher- ratio and the average-classsize to the maximum acceptable limit. If government tries to provide additional secondary schools without an aggressive mobilization of students into the existing ones, the cost burden of schooling on the government will be higher with its attendant social and economic consequences. For instance, government might find the continuous provision of other welfare needs unsustainable as more and more limited resources are diverted to the provision of new schools.

The study found that except for the average-class-size factor in the short-term, both enrolment and the studentteacher-ratio factors have significant negative impact on unit cost of secondary education in the state, indicating that economies of scale exist at all the sample levels. The result is in agreement with the findings of Babalola (1988) and Adedeji (1994) who identified teachers' salary cost p by the student-teacher-ratio and the number of students (enrolment) as major determinants of unit cost. The study however differs from both authors who found that average-class-size was an important factor in the determination of unit cost of schooling (Babalola 1988, Adedeji 1994).Nevertheless, in this present study, average-class-size variable is not found to be significant at 5 percent but is significant at $10 \%$. Nevertheless the three variables are squared, (i.e. long-run increases in size) they exert significant but positive effect on the unit cost of schooling at the aggregate level implying that additional spending on resources will be incurred as the size factors are increased. Thus there is direct proportional relationship between cost and the size variables in the longrun.

The pupil-teacher-ratio which represents the number of students per teacher in the school has implication for cost since the number of teachers employed in most cases will be contingent upon the number of students available in the school. Similarly, the average class-size will be determined by the average number of students and classrooms available. The provision of additional classrooms will lower the average-class-size and hence increase the cost of providing additional classrooms.

On the cost-reduction effect of the three size factors, it is obvious that student-teacher-ratio has the highest unit cost reduction impact (N584.85k) among the three size factors in all the sampled locations as against N234.01k for average-class-size and N113.92k for school enrolment size. The result agreed with the work of Oguntoye (1999) who 
found that student-teacher-ratio had the highest impact on unit cost in Ogun State public secondary schools. Oguntoye (1999) therefore suggested an increase in the pupil-teacher-ratio to reduce the cost of secondary education. The high cost-reduction effect of the student-teacher-ratio factor is understandable because of the role of teachers' salary in the determination of unit cost in schools. Calloid and Lewin (2001) had maintained that the student-teacher-ratio factor is more likely to have cost-reduction effect on schools because of teacher salaries cost as against other schools size factors. Teachers' salary cost constitutes the highest recurrent cost determinant in secondary education (Akangbou, 1987; Ajayi, 1998; Ajayi, 2004 and Abagi and Odipo, 1997). Hence, increasing the student-teacher-ratio factor would lead to a reduction in the average operational cost burden on government and consequently provide greater opportunity of access to all the eligible school-age children. In line with the result, Calloids and Lewin (2001) suggested that by increasing the student-teacher-ratio in public schools, more graduates will not only be produced at cheaper cost, but more savings could be made. In the same vein Abagi and Odipo (1997) in related study found that Kenya Ministry of Education would have saved an estimated Ksh3.5 million if the pupil-teacher-ratio in public primary schools were increased to 40:1 from its current 30:1.

One important way of cost recovery in public secondary schools, would be to increase the size factors at least to the permissible and acceptable limit which is capable of generating savings that could compensate for the limited government budget. This implies that a higher level of secondary education can be achieved through increases in enrolment, average-class-size and student-teacher-ratio. This does not however suggest that funding of schools should depend on the size factors. However, savings that are generated from increasing the size of schools could be ploughed back to improve the overall quality and quantity of secondary education delivery. It is important to note that the number of students in schools is now being used by many countries as an a very strong index for measuring the level of educational development. This informed the need to direct efforts at fully tapping the potential for increasing access to the school age children population through an effective and efficient utilization of available resources. Rather than building new schools that could further strain the limited resources and increase the cost burden on the government, it is economical to increase the size factors in schools. The argument is that it is possible to teach more students more efficiently or at lower unit cost. However, it is important to define the limit of increasing size within the optimum and appropriate scale so that schools will not begin to face the problem of diseconomies. It seems possible however that in order to improve the recurrent unit cost, students in schools with overcrowded facilities could be redeployed to schools with very few students and under-utilized facilities. This will help as a policy option in reducing the need to invest in additional facilities and employing additional personnel. This is important in the light of the current economic realities facing the government. There is need therefore to consider the advantage of greater economic efficiency in the face of uncertain financial conditions facing the government. The magnitude of resources devoted to education mean that efficient operation of schools in essential. Though, inefficiency may be tolerated in some other public programmes where budget allocation is small, an improvement in schools' efficiency could save significant resources, given the size of education expenditure.

\section{Conclusion}

The magnitude of resources devoted to public education demand that efficient operation of schools at both the aggregate and individual school level is essential. While inefficiency may be tolerated in public programmes where budgets are small, a little improvement in school efficiency could save significant resources given the size of the education expenditure. Thus, the problem of inefficiency in the use of available resources, compounded by the relatively declining funding of secondary education has necessitated the need to fully exploit and maximize the use of available resources in schools. This will enhance control over the cost of schooling while at the same time, ensuring increased education opportunities for all children within the school age group. The study has therefore provided some basic information about the statistical relationship between the cost of secondary education and the size factors in Edo State public secondary schools. It provides an indication that there may be opportunities for improving cost-efficiency by taking advantage of the economies of scale through possible merger of small-sized inefficient schools. The study provides some evidence to believe that where feasible, small under-enrolled schools may be consolidated to improve cost-efficiency in the face of declining financial conditions from the government. From the empirical result of this study, we therefore conclude as follows:

Size factors had significant influence on recurrent unit cost of secondary education

- That significant saving can be made from increasing school size factors.

- The unit cost of education could be reduced through efficient utilization of resources. This could be achieved by increasing the school size factors: enrolment, average-class-size and student-teacher-ratio to their 
optimum capacity. Thus, the three size factors are important in the determination of the behaviour of unit cost in schools. In specific terms, all the variables are important in the reduction of unit cost in schools.

A unit increases in the student-teacher-ratio factor lower recurrent unit cost more than a unit increase in the average-class-size and enrolment. Average-class-size and enrolment are next in that order.

Rather than building new schools which could increase the cost burden on the government, it will be more costeffective to exhaustively increase the existing school size factors to the optimum level so as to reduce cost and minimize wastages in public secondary schools in the state.

\section{References}

Abagi, O \& Odipo, G 1999. Discussion papers no DP004/97. Institution of Policy Analysis and Research. House Nairobi, Kenya.

Adedeji, S.O., Olaniyan O. \&Owoeye J.S. 2001.Managing School Resources for Better Learning Outcome in Osun State Secondary Schools. African Journal of Educational Management 9(1): 1-11 Department of Educational Management, University of Ibadan.

Adedeji, S.O., Olaniyan O. \&Owoeye J.S. 2001.Managing School Resources for Better Learning Outcome in Osun State Secondary Schools. African Journal of Educational Management 9(1): 1-11 Department of Educational Management, University of Ibadan.

Adenuga, A.O. 2003. Educational Expenditure and Performance in Nigeria (1970-2000). Human Resource Development in Africa.Nigerian Economic Society. Department of Economics, University of Ibadan, Nigeria.

Adenuga, A.O. 2003. Educational Expenditure and Performance in Nigeria (1970-2000). Human Resource Development in Africa.NigerianEconomic Society. Department of Economics, University of Ibadan, Nigeria.

Ajayi, A.I. 1998. Unit Cost of Secondary Education and Students' Academic Achievement in Ondo State, Nigeria (1991-1995). Unpublished Ph.D.Thesis.Department of Educational Management, University of Ibadan.

Ajayi, K. 2004. Teachers' Mandate on Education for Social Development..New Directions in the Production and Retention of an effective Teaching.D C. Elaturoti and Kola Babarinde (Eds) Teachers' mandate on education and Social Development in Nigeria. Faculty of Education stirring- Horden publishers Ltd.

Akangbou SD 1986. Financing higher education in Nigeria. Ibadan University of Ibadan, Faculty Lecture.

Carnoy, M. 1999. Globalization and educational reforms. What planners need to know.UNESCO? http//www.unesco.org.IIEP. Retrieved May 2002.

Charkraborty, K., Biswas, B., \& Lewis, W.C. 1999. Economies of Scale in Public Education. An Econometric Analysis. Economics Research Institute, Study Paper ERI 99-119.

Cohn, E. 1979. The Economic of Education.Balitunger Publishing Company.

Cotton, K. 1996. School size, school climate and students' performance.Schools improvement research series. Close-up no. 20 retrieved March 2005 from http/www.nwref.org/scipe/sirs/10/0020/html.

Edo State Directory of Public Secondary Institution 2008.

Federal Ministry of Education 2007.Statistics of education in Nigeria Federal Republic of Nigeria.

Federal Ministry of Education 2009.Statistics of education in Nigeria Federal Republic of Nigeria.

Federal Office of Statistics 1999.Social Statistics in Nigeria.NERDC, Lagos.

Federal Republic of Nigeria 1994.Federal Office of Statistics Social Statistics in Nigeria. Lagos NERDC

Federal Republic of Nigeria 2004. National policy on education (4th Ed). Lagos NERDC.

Ibukun, W.O. 2004. Management of Secondary School Education in Nigeria: Problems and Challenges. In E.O. Fagbamiye, J.B. Babalola, M. Fabunmi and A.O. Ayeni (Eds) Management of Primary and Secondary Education in Nigeria. Nigerian Association of Educational Administration and Planning (NAEAP).

Isuku, E.J.andEmunemu B.O 2012. Increasing Access and Reducing Operational Unit Cost in Public Secondary Schools in Edo State, Nigeria. An Empirical Analysis. West African Journal of Education (WAJE) Vol. xxx11 114-128

Lewin, K. 2001. Are Higher Secondary Enrolment Rates Achievable? In Keith Lewinand Francoise Caillods (Eds).Financing Secondary Education in Developing Countries; Strategies for Sustainable Growth.UNESCO International Institute for Educational Planning.

Lewin, K. 2001. Are Higher Secondary Enrolment Rates Achievable? In Keith Lewinand Francoise Caillods (Eds).Financing Secondary Education in Developing Countries; Strategies for Sustainable Growth.UNESCO International Institute for Educational Planning.

Ministry of Education Edo State 2007.Department of Planning, Research and Statistics.

National Bureau of Statistics 2007.Annual Abstract of Statistics. Federal Republic of Nigeria.

Turtel, P.A. 2006. Potential Efficiency from consolidation of Maine's Schools. Educational Research. 02. 3: 64-75. 